\title{
Access Limitation to Health Services in Palestine and Its Consequences on Palestinian Mental Health and Wellbeing: Literature Review
}

Mohammad Marie ( $\sim$ m.marie@najah.edu )

An-Najah National University https://orcid.org/0000-0001-5153-3112

Maher Battat

An-najah National University Faculty of Medicine and Health Sciences

Research

Keywords: limited health access, health care services, barriers, mental health, Palestine, Palestinians, Gaza Strip, West Bank.

Posted Date: April 19th, 2021

DOI: https://doi.org/10.21203/rs.3.rs-167116/v3

License: (c) (i) This work is licensed under a Creative Commons Attribution 4.0 International License. Read Full License 


\section{Abstract \\ Background:}

Accessing health care services system is a fundamental right for all people worldwide. The WHO has defined the obstruction of the availability, access, and delivery of therapeutic and/or preventive health services as a form of health attack. The Palestinian Authority faces significant challenges to ensure the sustainability of the delivery of its health services systems. The blockade of the Gaza Strip and the presence of Israeli settlements in oPt (occupied Palestinian territories) and the Separation Wall around Jerusalem all these obstacles affect the patient's right to access health care services. Palestinian Patients need permit applications from Israeli authorities that require usually 7-10 days depending on the case condition and the appointment from the target hospital in which the permit may be approved or denied or delayed. It has become a complex process due to the need to cross barriers or border crossings and restrictions on the movement of Palestinian patients and ambulances imposed by the Israeli government. Therefore, barriers policy to accessing health care services are a serious and permanent condition that can lead to a very stressful atmosphere and result in developing mental problems. This paper aims to provide an overview of the literature and established studies on mental health consequences related to access limitations policy to health care services system in Palestine.

\section{Methods}

PubMed and Google Scholar were used to search for materials for the literature review study. The Data in this literature review was collected by searching in electronic databases such as PubMed and Google Scholar. The keywords used in the searching process are Mental Health AND consequences AND limited access OR Access Limitations AND health care services OR health care AND barrier AND Gaza strip OR West Bank AND Palestine. Full-text articles critically appraised were included while the duplicated papers were extracted. The papers in this review follow the IMRAD style (Introduction, method, results, and discussion section).

\section{Results}

More than 25 related materials founded including review studies, 3 WHO reports, and 2 Palestinian government statistical reports.

\section{Conclusion}

Evidences from this review show that there is a necessity to maintain justice and equality among the Palestinian population and their right to freedom. Limited access to health-care services for Palestinian patients living in Gaza Strip, West Bank ,and East Jerusalem affect negatively the patient's quality of life and mental health mainly due to the Israeli Separation Wall besides road closures.

\section{Background}

Historical Palestine includes occupied lands by Israel in 1948 and 1967. Palestine is located in the eastern Mediterranean region that includes the occupied Palestinian territories contain both the Gaza Strip (along the Mediterranean coast) and the West Bank (the area west of the Jordan River). [1]. The Gaza Strip and the West Bank are geographically separated due to Israeli occupation, so Palestine remains a conflict zone. [2]

The material and legislative division of Occupied Palestinian territory (oPt), both in terms of the separation of the Gaza Strip from the West Bank and the fragmentation of the occupied West Bank into areas A, B, C and Israeli control in Area H2 in Hebron and East Jerusalem following the Oslo II Agreement, with Palestinian civilians and military control in Area A; Palestinian civilian control and Israeli military control in Area B; and Area C Israeli civilian control that led to the expansion of its settlement infrastructure. While development efforts have led to having 300,000 Palestinians living in the area including the development of health services, which have been severely hampered. In addition to the Palestinian civilians who stay in East Jerusalem inside the Separation Wall. After 1967, Israel incorporated East Jerusalem into the Jerusalem municipality; according to its residents for Palestinians who live in the East Jerusalem and can move freely within Israel, while most Palestinians from the rest of the oPt need permits to enter Israel 
(occupied areas of historical Palestine since 1948).The permit is required to cross the main barriers through the Separation Wall, as the Qalandiah barrier for Palestinians from the West Bank going to east Jerusalem. The Eriz barrier for Palestinians from Gaza Strip going to East Jerusalem and to West Bank through the Qalandiah barrier too. A different situation for Palestinians in the rest of the oPt presented significant difficulties for the cohesion of the health system and the access of staff, ambulances, patients and their relatives.[3]

Israel's construction of the Separation Wall since 2002, controlled the infrastructure and restricted the fuel supplies and access to water and sanitation. Palestinians are tortured in Israeli prisons, humiliated at Israeli barriers, and their dignity is not respected [2]. The Separation Wall and barriers complicate Palestinian access to work and to health-care facilities. Taking alternative roads to nearby towns and health facilities between the Green Line, which separates Israel from the West Bank and the Wall. Poverty rates have risen sharply, and nearly half of Palestinians depend on food aids. The social cohesion that kept Palestinian society intact, including the health-care system, is now tense [2] [3]. In the other hand over 700 obstacles on the roads that control the Palestinians movement in the West Bank include 140 barriers that are permanent infrastructure, but only 64 are equipped with permanent security forces, including 32 barriers located along with the Separation Wall or on roads leading to Israel, and 20 barriers in the Israeli-controlled area in the city of Hebron, and another 12 points elsewhere in the West Bank [4]. The other 76 (partial) barriers are either operating from time to time or having security personnel present in a tower. And the main barriers for Gazan patients are the Erez barrier crossing into oPt and Israel, the southern Rafah Crossing into Egypt. [4]

Palestine is one of the 50 countries with global conflict, since the past three decades that conflict impacts the civilian health needs access [5], along with reduced infrastructure affecting the quality of life of Palestinians, including insecurity, inequality in access to all forms of health care, services, and health. [2]

The organizations of health care in Palestine include primarily: the Government of Health Organization (Ministry of Health), United Nations Relief and Works Agency (UNRWA), and Palestinian Red Crescent. UNRWA provides primary health care to Palestinian refugees, a non-governmental organization that provides third-degree primary care services, particularly in East Jerusalem, and secondary care services, to a lesser extent, some primary health-care services [6]. The UNRWA for Palestine Refugees in the Near East has been supporting Palestine refugees in the Gaza Strip and the West Bank since the 1950s. Because of conflict and violence, occupation, high levels of poverty and other social determinants of health that threaten the well-being of Palestinian refugees [7]. The Palestinian Red Crescent, which provides ambulance services and some clinics, and the private sector that covers private doctors, is new to the health service delivery sector in Palestine. There is a lack of effective coordination between these different sectors, and there is a severe shortage in many areas for instance: child protection, mental health, and child disability services [6]. There is also a shortage of medical personnel in many sectors and specialties in neurology, oncology, pediatric surgery, and psychiatry [8] such as schizophrenia [43] and anxiety patients [44]. Soothe Palestinian Ministry of Health refers patients of the West Bank and Gaza Strip to specialized care institutions whenever the service is not available in the local Ministry of Health hospitals, and financially covers their treatment in outpatient medical facilities from external help [8]. According to the Palestinian Central Bureau of Statistics in 2016, about $82 \%$ of the Palestinian population living in the West Bank and Gaza Strip are covered by some form of prepayment of health care. The main providers of health coverage, namely government health insurance and the UNRWA for Palestine Refugees in the Near East, account for more than $90 \%$ of the coverage provided; in addition, the ministry of health gives some cases a $100 \%$ governmental coverage as oncology cases referrals [3].

Most referrals are made to private/non-profit health facilities in the oPt, while one in five cases referred tithe surrounding countries such as Egypt, Israel or Jordan [8].Referrals to Egypt have steadily declined and Jordan has almost stopped in response to the policies of these governments: Egypt has restricted Palestinian access across the Rafah border (between Gaza Strip and Egypt) and Jordanian hospitals have refused to accept new Palestinian patients from the Ministry of Health, because of outstanding debts. As a result, referrals to Israel, which are paid indirectly through deductions from Palestinian customs revenues held by Israel, and referrals to non-governmental facilities within the West Bank and East Jerusalem hospitals, have increased sharply. [8]

The Palestinian Government health insurance covers: primary services including maternal and child health services, secondary care, drug prescription on the list of essential medicines, and referred cases to the non-governmental institutions. UNRWA provides services to Palestinian refugees in the oPt and covers comprehensive primary health services, with limited support for hospital care. About $38 \%$ of health funding comes from payments from private funds, The Palestinian Authority faces significant challenges to ensure the sustainability of its health services delivery, with little control over many natural resources in the oPt, lack of sovereignty

Page 3/17 
over tax revenues for health financing, and lack of full control over health spending on referrals to Israel, and the high level of donor accreditation. [3]

In2013,the highest referral causes in the West Bank and Gaza Strip were Oncology, ophthalmology, and pediatrics especially from Gaza referring to cases of nuclear medicine and orthopedics, and West Bank for MRI diagnosis and internal medical conditions [8]. Oncology for Gaza patients also represents the highest total cost of referrals due to the length of hospital stay required for chemotherapy and radiotherapy and the high cost of medicines. A patient requiring radiation treatment must be referred outside Gaza because the import of radiotherapy equipment to the West Bank or Gaza requires special approval from the Israeli authorities, full access to technical maintenance, and substantial funding that is not available. Patients are also usually referred for chemotherapy because there are one or more ingredients unavailable in the protocols, about $(27 \%)$ of referrals are to Augusta Victoria Hospital (AVH), which is the most important destination, and the main referral center for cancer patients in the oPt. (25\%) to Makassed Hospital in East Jerusalem, which operates as a major center for pediatric tertiary care and cardiology. The most common and important destinations in hospitals after Makassed hospital is Hadassah Ain Karim hospital in Israel (7\% of permit applications); An-Najah National University Hospital in the West Bank (7\%); Tel Hashomer in Israel (6\%); and St. John's Hospital in East Jerusalem (4\%). [3][8]

Oncology or cancer treatment and the diagnosis was the largest medical specialty for patients requiring permits to leave Gaza in 2017, accounting for about one-third (31\%) of the applications of patients in Gaza. Other major disciplines include pediatrics (9\%), heart disease (9\%) Hematology (9\%), orthopedic surgery (7\%) and Ophthalmology (7\%). [6]

Gaza Strip lacks radioisotope diagnostic services and radiotherapy because of Israel's very restrictive policies that control the movement of people and goods to Gaza, as well as because of the poor financial status of the Palestinian Ministry of Health [8]. The main hospital in Gaza, AlShifa Hospital, had planned to establish a special radioisotope center in 2003, for nuclear medicine services, but was unable to secure funds from donors or guarantees from suppliers to provide material needs and human resources. These restrictive circumstances have led to the current situation of the lack of trained doctors and technicians to support services, as well as the lack of equipment and radioactive isotope materials, some of which Israel considers 'dual' and therefore subject to lengthy coordination procedures [8]. When Patients require access to medical health services, and they are not available in Gaza Strip they must go through a long bureaucratic process so that they can apply for such a permit. Once the patient's doctor understands the patient's need for referral, he must first submit an application through the Purchasing Services Unit of the Palestinian Ministry of Health, which will review the patient's application and, if approved then they can, make an appointment at the hospital and issue financial coverage to refer. After that, the patient can apply to the Israeli authorities through the Palestinian Health Liaison Office in Gaza. [8]

In 2017, According to a Report of a field assessment of health conditions in the occupied Palestinian territory: patients applying to use health care from Gaza had the lowest approval rate and delay than before. Permit denial or delay among Gaza patients/companions to access hospitals outside the Gaza Strip was higher for a young age compared with children below 17 years old and older age more than 60-year-old. [8]

Access to health care remains difficult because of health attacks imposed through restrictions on movement. In 2017, seven mobile clinics providing primary care to these communities were denied access for more than two months to more than nine months. WHO defines a health attack as 'any act of verbal or physical violence, the threat of violence or other forms of psychological violence, or obstruction of the availability, access, and delivery of therapeutic and/or preventive health services. [9]

According to Regional Office for South-East Asia of World Health Organization, when patients need to travel to other cities to access health care, they need a person to accompany the patients. However, less than half of companions permit applications (44\%) were approved in 2017. Over half of them (52\%) were delayed and $4 \%$ were denied. However, there was an increase in the proportion of the permits delayed. A manual examination of applications made at district offices in the fourth quarter of 2013 revealed, that the most common Israeli reason for denial of access was for 'security' reasons. $35 \%$ of relatives who had applied to accompany or visit patients were denied for 'security' reasons, because they were not close enough to patients. $(20.2 \%)$ were denied the permit because of another illness. $7 \%$ were denied because another relative had applied for a permit to accompany the patient. The reasons for refusing entry permits to patients in the West Bank varied, including: Rejected for security reasons, no medical report, suspected fake reports, no reason, need hospital confirmation, mistaken identity, treatment available in the West Bank, wrong 
address, incomplete documentation, invalid magnetic card (card contains personal information taken from Israeli authority with expiry date determine the number of visit to Israel and East Jerusalem). Additionally, in December 2013 the reasons for denying access permits to patient - companions in West Bank concluded as the following: Rejected for security reasons, the wrong close relationship from the Israeli perspective, unknown reason, additional companions list statement, Suspected faked documents, wrong identity, incomplete documents, wrong address, no hospital confirmed application, need a detailed medical report. [9]

Concerning delayed permits, the Israeli authorities in Erez (Barrier to travel outside Gaza through Israel to East Jerusalem and West Bank) do not provide reasons for refusing a health permit. When permits are delayed after the hospital appointment date, the reasons are sometimes written: Unknown, no response, still under study $28 \%$, must change companion $15 \%$, needs a new hospital appointment $14 \%$, waiting for a security interview appointment $8 \%$, and waiting after a security interview $13 \%$, not suitable for referral outside $3 \%$, a new application needs $2 \%$, returned medical papers $1 \%$. [8]

In summery the Palestinians living in West Bank and Gaza Strip face many difficulties to access health care services, including Gaza patients in need to travel outside Gaza (East Jerusalem, West Bank or other countries as Egypt) and patients from West Bank in need to travel to East Jerusalem to access health care.These difficulties have many effects on Palestinian quality of life[2][6] [8]and increase the stress levels. This study aimed to provide an overview of the mental health consequences related to access limitations to health care services in Palestine.

\section{Methodology}

The Data in this literature review was collected by searching in electronic databases such as PubMed and Google Scholar. The keywords used in the searching process are Mental Health AND consequences AND limited access OR Access Limitations AND health care services OR health care AND barrier AND Gaza strip OR West Bank AND Palestine. The search process shows in Appendix A. full-text articles critically appraised were included while the duplicated papers were extracted. The papers in this review follow the IMRAD style (Introduction, method, results, and discussion section). More than 25 related materials founded including review studies, 3 WHO reports, and 2 Palestinian government statistical reports. The characteristics of the included article studies are presented in table Appendix B.

\section{Inclusion and exclusion criteria}

Studies were eligible for inclusion if they satisfied the following criteria: the articles discussed the access limitations to health care services either in West Bank or Gaza Strip and mental health consequences.

\section{Violation of the right to access health care services for Palestinians from West Bank and Gaza}

One necessary life element is having access to health care services; it's also a fundamental human right [9]. Inadequate access to health care can be determined to health [10]. No individual shall get denied to access healthcare services in his/her country, or to get arbitrarily denied when need to leave their country to get health care abroad, the right to have sufficient healthcare is one of the most respected and widely recognized human rights and dedicated in major international laws and conventions as a 'fundamental human being' the indispensable right to exercise most other human rights.' [11] The minimum basic obligations of the right to health, the right to access health facilities and services on a non-discriminatory basis, particularly for vulnerable or marginalized groups. [12]

Referrals and access to tertiary care have a dimension in human rights. In most countries, referral to tertiary care is a simple internal procedure primarily affected by the availability of service capabilities and insurance considerations. In the oPt, it has become a complex process due to the need to cross barriers or border crossings and restrictions on the movement of Palestinian patients and ambulances imposed by the Israeli government. Access to tertiary health care is limited by many obstacles. Data on the referral and authorization process are available from different sources. According to the measures adopted by the security cabinet of the Israeli government, the number of road closures, barriers ,and roadblocks increased, in addition to scrutiny and delay in the existing barriers increased. Military barriers were set up next to Augusta Victoria and Makassed and St. Joseph hospitals in East Jerusalem, which negatively affected its work, such as delaying the arrival of staff and patients. [13] 
The Israeli military occupation of the West Bank and Gaza Strip and the annexation of East Jerusalem, oPt contrary to international law; limit the movement of Palestinians within and between these areas. Access to specialized health care by multidisciplinary communities is hampered by the Israeli authorities' access to permits and restrictions on travel routes, with increased cost and time resulting from the blockade of the Gaza Strip and the presence of Israeli settlements in oPt and the Separation Wall around Jerusalem all of these obstacles affect the patients right to access health care services. [10]

In 2018, the Human Rights Council reported that the situation of the Palestinians in the West Bank and the Gaza Strip posed a 'serious' threat to the peace process due to the Israeli occupation. [10] and in 2017, Right to health access indicators for the West Bank: 74,400 West Bank referrals to East Jerusalem and Israel, $18 \%$ of patient companion applications denied access, $90 \%$ of the 2,125 ambulances trips requiring entry to Jerusalem denied direct access, 40,220 referrals to East Jerusalem hospitals from the West Bank and Gaza, 174,444 people in Area $\mathrm{C}$ served by mobile health clinics, $12 \%$ patients denied health access to East Jerusalem and Israeli hospitals. And the Right to health indicators for Gaza:12,075 patients exited via Erez, $56 \%$ of patient companion applications denied or delayed access through Erez, 1,405 exited Rafah terminals (Israeli barrier) for health reasons, Rafah terminal open for the exit for 21 days over the year, $46 \%$ of patient applications denied or delayed health access out of Gaza via Erez[10]. Only one companion is entitled to a permit at that time for Gaza patients, which places a burden on escorts while patients are hospitalized for a long period. Other relatives may also want to visit patients, especially during long stays in the hospital and if the patient is about to die. This is particularly difficult for child grandparents and other elderly companions who have health needs themselves. As a result, people suffer in the organizing process to bring an ambulance to the barrier and preventing them from entering Jerusalem and checking process at the barriers that reflect mental health suffering. [8]

On the other hand, Palestinians in Gaza and the West Bank, including East Jerusalem, faced demolitions of homes [46]and schools, arbitrary arrest and detention, and restrictions on freedom of movement affecting all aspects of Palestinian life, from access to medical care that leads to a significant and negative impact on the psychological well-being of the population and mental health. Also these restrictions lower welfare levels, the economy, and impact on psychosocial aspects. [10]

\section{Health care access condition in Palestine (oPt)}

Ministry of Health referrals approval procedures can take a long time. It took days to months in some cases. According to report of a field assessment of health conditions in the occupied Palestinian territory in 2017Security requirements for the Israeli permit process: Patient files are checked individually and patients may be required to attend a special security interview as part of the licensing application process. West Bank patients must obtain valid magnetic biometric cards from Israeli military authorities in the West Bank before applying for a health access permit. Even patients with serious conditions, unless there is an emergency, must apply personally. Multiple permits to continue the course of medical treatment, For example, cancer patients who require accurate periods of chemotherapy or radiation therapy must apply for a new permit for each appointment at the hospital with a risk of being rejected or delayed each time, which can have serious health consequences. Patients must walk through barriers and carry their personal belongings, unless they are transported in an ambulance. This process can take a long and tiring time for elderly, seriously ill, and disabled patients who use medical equipment and new mothers with infants.

Patient referrals process needs:

1. Medical decision.

2. Medical approval.

3. Financial approval.

4. The appointment date from the hospital indicated by patients according to the urgent situation.

5. Applying for a license from the Israeli Authority.

6. The process of authorization: Israeli coordination up to the date of the permit according to the patient's appointment.

7. Gaza patients need to cross the Erez checkpoint to obtain health care in the West Bank.

8. Receiving health care.

9. Traveling backward. 
Rearguing the last point, Gaza patients visiting the West Bank through the Erez checkpoint must also cross the Qalandia checkpoint (located between West Bank and East Jerusalem south Ramallah city), which increases the probability of delays and violence. [8]

Patients applying for permits from the Israeli authorities face additional financial burdens, including travel costs and accommodation costs for their comrades, as well as the emotional stress of a process lacking transparency, unpredictable and often long, as the process needs time waiting for months. On the other hand male patients aged 16 to 55 years and female patients aged 16 to 45 years face additional, long security clearance processes, while all patients and fellow patients called for security questioning as a prerequisite for allowing treatment. [8]

A survey conducted in 2007 and 2008,examined the impact of a lifetime and past 30-day experiences of political violence on the mental and physical health of adult Palestinian women from the West Bank, Professional translators in the West Bank translated the survey from English into Arabic, reported that their access to health care had suffered as a result of the political violence of the occupation forces, $27.5 \%$ reported being threatened by Israeli forces and Palestinian mental health affected.[14]

The health situation in the oPt remains affected by the Israeli occupation. The long-term blockade and serious restrictions imposed by the occupation, affect the physical and mental health of the population as well as the further development of quality health services, especially in the Gaza Strip by increased stress levels. This was exacerbated by the internal Palestinian political division and the financial crisis of the Palestinian Authority. [13]

A cohort study conducted by Vitullo A, et al 2012. used quantitative and qualitative approaches aiming to describe and analyses the experiences of Palestinians in the West Bank and Gaza Strip who applied for permits from the Israeli authorities during 2011, either to access health care or for travel to work in Palestinian hospitals in East Jerusalem, data for patient referrals were obtained from the Palestinian Ministry of Health; data for permit applications and responses were obtained from the Palestinian General Authority of Civil Affairs, West Bank and Gaza Strip, and hospitals in East Jerusalem. The results conclude that the Palestinians who have been transferred to Jerusalem or from the Gaza Strip to West Bank hospitals need permission to enter and access health care services. However, there are restrictions to grant Palestinians permission from the Israeli government that does not have any standards for it and the clearest denial is for security issues. Patients who are between the ages of 18 and 40 years old had the highest rate of rejected or delayed military permits. Interviews conducted with families of patients in Gaza, whose permits were denied or delayed showed that six patients died while waiting for permits that affect the patient's quality of life negatively and lower mental health. [15]

In a descriptive study of the quality of life assessment using a tool from WHOQoL-Bref, conducted by Mataria A, et al, 2008.the design of multi-stage cluster samples for 1,023 adult Palestinians, from the general population living in the conflict zone in the West Bank and Gaza Strip from the end of 2005 to 25 January 2006,concluded that Palestinians suffered from poor quality of neighborhoods due to restrictions on access to health care services due to barriers in the Separation Wall and closures, and in some cases lead to psychological and physical distress and death. [16]

Besides ambulance delays due to Israeli barriers and road closures, the most vulnerable groups in Palestine include women during pregnancy and childbirth; children and infants; the elderly, and the chronically ill patients or disabled. Knowing that access to health services can be difficult and risky is also an additional psychological stress that can directly affect health. [17][18]

\section{Health care access limitations regarding women and children}

The Palestinian population living in the occupied territories is subjected to ongoing violence as a result of this ongoing crisis. Palestinians, particularly women and children, are suffering from severe psychological distress. Although these patients need immediate and urgent care, usually mental health and social support, access to health care remains difficult because of the settlement policy and the creation of pockets [19]. An example of the unique characteristics of this health conflict is the monitoring of birth rates at Israeli army barriers for those who are unsuccessfully trying to reach a health facility to provide Birth. The wellbeing of people living in this conflict zone is largely affected due to difficulties in access to health-care services, mortality and morbidity increased too [20].Another study conducted in 2007 for 2,158 women living in the West Bank and Gaza Strip by Regression analysis demonstrated the association between dissatisfaction with the place of birth and the selected determinants. Concluded quality of life, well-being, mortality, and morbidity were adversely increased by limited access to health-care services resulting from continued closures and blockades. [21] 
Moreover, in a study analyzing data collected from four surveys conducted by the Palestinian Central Bureau of Statistics covering fifteen years (2000-2014) for children (no. 16793) and women (no. 8477) in five areas of the OPt, the conclusion that the location is important with the results shown The negative impact of the severity of the conflict on access to care, particularly in the southern West Bank for maternal health services and the central West Bank vaccination. The government's policy of reducing the number of people who have been displaced by the conflict has been reduced. Besides, psychological barriers to access to services are increasing because safety concerns can prevent people from trying to access services that increase the psychological stress of patients and adversely affect their quality of life, and had fear concerns and unstable life conditions. [22]

Moreover, restrictions lead to stress and psychological effects have shown from the story of Halla Shoaibi of the University of Michigan in Ann Arbor in the United States, estimates that in the period studied (2000-2007), 10\% of pregnant Palestinian women were delayed at barriers while traveling to the hospital to give birth. One result has been increased dramatically in the number of home births, with women preferring to avoid road trips while in labor due to fear of not being able to reach the hospital in time. Their fears are well-founded. Shoaibi said 69 babies were born at barriers during those 7 years. 35 babies and 5 of the mothers died an outcome which she considered to amount to a crime against humanity. [23]Barriers continue to have economic, medical and psycho-social effects on Palestinian pregnant women [24]. By year review about worst abuse against Palestinian children in 2017 twelve Palestinian children died from Gaza due to insufficient access to health care, eight of whom were less than two weeks away due to these pediatric cases prevented from leaving Gaza for medical treatment by rejecting or delaying patients 'requests and their families suffered. [25]

A Regression analysis established the association between dissatisfaction with the place of birth and selected determinants of 2158 women residing in the West Bank and Gaza Strip. The study reported dissatisfaction with their childbirth location referred to the following reasons: $37.5 \%$ of respondents stated that the availability of health insurance and the low cost of services were among the main reasons; $19.3 \%$ stated that they were unable to reach the preferred place of birth due to sudden birth; $13.7 \%$ stated that reaching the Israeli army impeded access (closures, blockades, and barriers that prevent the movement of people and goods). $14.1 \%$ reported that there was no other place available for them to give birth. And $11.7 \%$ other reasons, Palestinian women are concerned about frustration at the lack of certainty of their ability to access the maternity care center. This means living with constant anxiety during their pregnancy where they will go when labor begins, and how they will return to their families. Lead to inducing a severely stressful atmosphere. [26]

According to a report of a field assessment of health conditions in the oPt, data collected in November 2015, indicates that some accessibility to some special health services is two to four times more likely to be rejected: orthopedics, neurosurgery, general surgery, and psychiatry, among others. East Jerusalem hospitals remain the main referral hospitals for Palestinians. The system of permits and barriers adversely affects patients in need of care in the six East Jerusalem hospitals or in Israeli hospitals that provide specialized health services that are not available elsewhere in the oPt. The government's efforts to address the problem of child labor are also being addressed. $11 \%$ of women in the West Bank have unmet family planning needs. Barriers to access to healthcare facilities are a serious, permanent and well-documented problem including mental health problems. [27]

Finally In a literature review study in 2017 for Palestinian children, explored that 5 million Palestinian refugees currently live in Palestine, Jordan, Syria, and Lebanon, about $40 \%$ of whom are children. Palestinian child mortality rates are similar to neighboring Arab states. They are largely affected by the occupation, which has increased violence against children, mental health problems, and malnutrition, particularly in Gaza, which is suffering from a health crisis. Children's access to health care in Palestine is restricted as a result of the requirement to obtain an allowance paper to travel to Jerusalem, where there are specialized hospitals for example; Augusta Victoria Hospital in East Jerusalem provides the only treatment for pediatric patients, including hematology, oncology, radiation and kidney diseases. Because of permit restrictions and limited access to males, most children receive care with a grandmother or aunt (sometimes the parent's age is less than 50), which increases the psychological burden of children and violates their parents' rights to care supported by their parents, additionally; they feel insecure, had nightmares and aggressive behaviors lead to mental health problems. [6]

\section{Health Care Access limitations for the Political Palestinian Prisoners in Israeli prisons}

A Report of a field assessment of health conditions in the oPt in 2015 shows the population of the oPt suffers from threats to their mental health including prisoners. The main issues of concern regarding the physical safety of the detainees and the 6,066 
Palestinian security prisoners held in Israeli prisons are lack the access to adequate medical care promptly, whether by diagnosis or treatment and lack of adequate medical care besides inadequate nutrition, housing conditions and denial of family visits and contacts. Physical and psychological abuse leads to severe mental health problems and great pain. The use of arbitrary punishments and administrative detention without trial are important problems for many prisoners. The evaluation team was unable to access Israeli prisons and Palestinian prisoners there and was unable to independently verify the reported conditions [13]. Moreover, the prisoner experiences mental health problems as a result of care negligence as an acute hysterical reaction in case of interrogation methods employed by Israeli interrogators, and acute depression and severe introversion related to the prisoners being disconnected from their families, and suicide as a result of severe psychological stress, and anxiety, insomnia occurred too.

\section{Health care access difficulties for Palestinians living in West Bank}

Most of the Palestinians from the West Bank can no longer access specialized health care services in East Jerusalem, and in some cases in certain military conditions, can't access hospital in other cities in West Bank due to movement restrictions that reflect the lack of freedom, as a result, affect their quality of life. [18]The over-60 age group accounted for $23.3 \%$ of referrals in 2015, although they accounted for only $4.5 \%$ of the population, reflecting the burden of non-communicable diseases. For Palestinians from the West Bank - except for East Jerusalem - and the Gaza Strip, medical referral centers in East Jerusalem can only be accessed after a permit from the Israeli authorities, a complex process that can lead to delays and denial of adequate care. In 2015 , more than half of the referrals were from the Ministry of Health to destinations requiring access permits. [15]

In 1998-2007, Analysis of the Geographic Information System (GIS) for Childhood Cancer, recorded and access to health care in the West Bank, Palestine shows low- and middle-income countries, it is difficult to record high-quality diseases in the development of inadequate health care infrastructure and instability whether politically or economically. This article explored the potential of GIS to add value to understanding childhood cancer patterns in the West Bank, despite a variety of obstacles to disease registration. The result shows that the cancer patient faced many difficulties in receiving cancer care that transports them from hospital to hospital because of the lack of all services established in all areas such as bone marrow transplantation and radiation therapy only at Augusta Victoria Hospital in East Jerusalem besides they need to get a permission to cross the Israeli checkpoint and if they have security issues they are not allowed to enter East Jerusalem. The large proportion of cases with death certificates compared to other records is another indicator of the number of cases that do not reach or exceed major treatment centers in the West Bank. [28]

A review study for 43 articles in Palestine in the West Bank in 2016, aimed to examine the mental health needs of Palestinians and the availability of services, concludes that unstable conditions for Palestinians affected their mental health due to lack of access to basic needs, such as health care services due to geographical difficulties, 'Separation Wall', lack of freedom and restrictions on movement and political conflict between Palestinians and 'Israeli' Jews. There is a need for mental health care and resilience improvement for Palestinians. [29]

A qualitative study conducted in partnership with the Palestinian Medical Relief Society (PMRS), a Palestinian health care nongovernmental organization in the West Bank in 2011, Data collection included participant observation, analysis of secondary data, and semi-structured interviews with key informants, concluded that Palestinians face difficulties in accessing health care services, either by preventing or delaying them due to restrictions on the movement of patients and health-care workers, who need permission from the Israeli authorities to cross barriers through the Separation Wall. Some of the patients' companions are not allowed to cross barriers due to Israeli security issues or the absence of a clear reason for delay, depriving them of basic health care needs. On the other hand, this difficulty limits access to medicines and medical equipment. Delays caused by the checkpoint led to the death of Palestinian patients, with ambulance drivers reporting that they faced violence and were denied access to patients in some emergencies, particularly injuries caused by the Palestinian-Israeli conflict, in which civilians were physically and verbally abused by soldiers. Health care providers in ambulance risk for injury and death. As a result, the Palestinians have become unsafe and increase the level of stress of 'moral suffering' and there is an impact on the work of health-care providers who need access to health-care places through barriers or road closures on a daily basis [5]. For example, nurses in Palestine face many difficulties to access their workplace due to barriers [30].Doctors, community health workers, and nurses reported that the persistent psychological pressures of the occupation accelerated the deteriorating effects of many chronic diseases. One of the doctors said, "At barriers, they try to humiliate you because you are a doctor". The medical staff faced delays, harassment, torture and abuse. This occurred primarily at checkpoints but also elsewhere [6].Access to mobile health clinics in 2017, seven mobile health clinics run by three health providers were denied access to communities in Area C of the West Bank due to health attacks. [9]

Page 9/17 


\section{Health care access difficulties for Palestinians living in Gaza Strip}

According to report of a field assessment of health conditions in the occupied Palestinian territory in 2017, the Palestinian Coordination Office in Gaza obtained data on Israeli responses to requests for patient permits to travel outside Gaza to obtain health-care services through the Erez barrier. The Palestinian General Authority for Civil Affairs obtained data on Israeli responses to all applications for health service permits and were classified by provincial coordination offices. The Gaza Strip has been under land, sea and air blockade for more than 15 years, with significant consequences for the health sector and access to health services. The majority of referrals in Gaza (77\%) require access through the Israeli-controlled Erez crossing to access hospitals in East Jerusalem and other parts of the West Bank and Israel. All these patients must apply to the Israeli security services for permits to leave Gaza to obtain primary health care. In 2017, the patient's permit approval rate reached its lowest level since 2006, with 54\% of patient requestions accepted - that is, nearly half of patients' requests were rejected or received no final response by the time of the hospital time. Access to emergency and emergencies can be handled on the same day, although processing time for these applications can take longer. For patient applications that have been reported as 'non-urgent', processing time is much longer. The Israeli authorities had previously required Palestinian patients to apply for permits prior 10 working days at least [8]. 6\% of referrals by the Ministry of Health in Gaza were to health care facilities in Egypt, requiring exit through Rafah. Access outside Gaza via Rafah remained limited in 2017, limited to humanitarian cases, including patients seeking health care in Egypt. [9]

In a cohort study done by Vitullo A, et al in 2012, Of the 168278 applications for health services permits provided to the Israeli authorities, $16.4 \%$ (12.8\% for patients and $19.5 \%$ for companions) were rejected or received no response. For patients in the Gaza Strip, requests for exit through the Erez checkpoint for a referral to medical care increased by $17 \%$ over one year to more than 22,000 , while the proportion of applications rejected nearly doubled (from $2.89 \%$ to $5.72 \%$ ). The number of referrals from the Gaza Strip to Egypt continued to decline in 2015 due to the closure of the Rafah border. The reconstruction of health facilities, particularly in the Gaza Strip, has been hampered by a lack of funds in addition to restrictions on the import of building materials and medical equipment. October 2015, escalating violence in the OPt has led to new roadblocks and barriers, restricting the movement of ambulances with consequent delays in access to health care. [15]

Increased bureaucratic delays in processing patient permit applications in 2017, and 596 patients and 91 sick companions were called in for security questioning as a precondition for access to health services outside the Gaza Strip [3]. On the other hand, there is failure in the health care system in the Gaza strip due to low infrastructure and workload especially in case of fire injury during demonstration events with Israeli Jewish at the Gaza Borderlines with Israel all of that lead to mental health deterioration. [31]

Restrictions on access to basic health services are one of the main obstacles to the right to health for Palestinians living in the West Bank and Gaza Strip. Restrictions affect cancer patients at a weak point in their lives when they need specialized care and services for diagnosis and treatment. Regarding cancer patients from Gaza, most of them referred to West Bank and East Jerusalem due to chronic shortages of medicines and lack of medical equipment in the Gaza Strip, after they diagnosed with cancer need to wait several months to receive treatment which the process of getting access permission from Israeli authorities to cross the barriers severely stressful. [32]

The following are examples showing patient's experiences for Oncology patients from the Gaza Strip with limitations to health care access, which reflect their suffering and that affect mortality and morbidity:

Samira, 64, was diagnosed with uterine cancer in 2016. She underwent surgery but then needed follow-up treatment not available in Gaza. Doctors referred Samira to radiotherapy in East Jerusalem. It takes her more than 6 months and 5 requests for permits to finally exit Gaza in June 2018. "All this time, I was suffering from abnormal bleeding. It was a matter of life and death. Why was the permit rejected?" She says.

Khadija, 32, mother of four, noticed something unusual with her breasts in December 2017. Doctors soon confirmed that she had breast cancer. In January 2018, Khadija applied for a permit to go to the Augusta Victoria Hospital in East Jerusalem a plastic surgeon - to see if cancer had spread and if so, to what extent. Her permission was rejected. She started receiving chemotherapy in Gaza, but there was a cosmetic need for optimal treatment surgery. In July, Khadija applied for a permit and was again rejected. She decided to change her medical destination to Egypt. Khadija's second attempt to leave Gaza into Egypt was finally successful. 
She underwent surgery in August 2018, 7 months after the diagnosis. These obstacles put her life at risk of death and increased her suffering [32]

Mohammed Abu Harbid, 54, was arrested in Erez on July 10 while returning to Gaza with the body of his brother Suleiman Abu Harbid, 58, who died in Tel Aviv's Akhlilov hospital from stomach cancer. His body was returned to his family in Beit Hanoun, Gaza, while Mohammed was detained for three hours in Erez, and his brother's funeral was lost. The brothers had traveled together to the hospital on June 16, 2013. [8]

The following are Examples of Gaza patients and patient-companions detained at Erez in 2013:

Patients and their companions face the risk of being detained while traveling through the Erez checkpoint, or after a security interview. The Palestinian Human Rights Organization reported that 5 patients and 5 patient companions were detained in 2013; 3 patients and 4 companions were still in detention in 2014. In the following paragraphs, WHO reports on two patients and 3 of his fellow detainees.

Detained husband: A 35-year-old woman from Gaza applied for a permit to cross Erez, after which she was called to attend an Israeli security meeting. When she arrived in Erez with her husband, the Israeli authorities asked her husband to attend a security interview instead. He was arrested, detained and got released in 2014 after 6.5 months in prison and after a court appeal. The patient sought local treatment for her eye aches while awaiting her husband's release and was able to leave Gaza for surgery. At the time of the interview, the family was unsure whether they would risk a new application for access to the Erez crossing. Son of the detained patient: The son of a 48-year-old disabled patient from Gaza was granted permission to accompany his mother to a Jerusalem hospital for bone surgery, but was arrested at the Erez barrier. The mother's medical treatment was postponed for 3 months. The son is still awaiting trial in Askelon prison.

Another example of a Patient detained for 12 days in Erez: Israeli security forces at Erez crossing detained a 24-year-old patient from Rafah suffering from hearing loss in both ears after he came for a security interview to obtain permission to travel to a hospital in East Jerusalem. He was interrogated for 12 days and then released. He had previously been referred for surgery in Egypt but was unable to travel there in August 2013 after the closure of Rafah. He remains untreated and at risk of total hearing loss.

Finally, a patient arrested at Erez barrier: A 33-year-old patient with chronic hepatitis, from Beit Hanoun, was referred for treatment at a West Bank hospital due to an ophthalmology condition. Israeli security forces detained him at the Erez crossing on his way to a hospital in Ramallah. According to his lawyer, he is awaiting trial and is in stable condition, but was not examined by an ophthalmologist and was only a general practitioner in the first days of his interrogation. [33]

In summary, the mental health and well-being of Palestinians is affected in particular, patients, who need to access health care services through Israeli barriers[16]. Mental health is negatively affected by the consequences of the difficulties to access health care services. which increases the psychological burden especially among children [2], increase psychological stress [22], emotional stress [6][9], affect palliative care especially for cancer patients [2][6][11][5], patients feel inequality [6], insecure and lack of dignity [12], mortality and morbidity increased [16][21], difficulties face women in childbirth impact women's psychological status [21][22] [26][27], also some of the patients die before accessing health care [17][20][6][11][3]. While patients from Gaza face more restrictions than patients from West Bank, affecting more negatively the Quality of life for Gaza patients.[6]

\section{Discussion}

Health inequalities generally define worse health outcomes in the Gaza Strip than in the West Bank. The Mental health of the population is adversely affected, with 312,000 children requiring psychosocial support in 2018 , mostly in the Gaza Strip. According to Charara R. et al 20017, Patients referred to facilities outside the Gaza Strip are exempt from the general travel ban imposed on Palestinians in the Gaza Strip, allowing them to apply for exit permits for health care. The occupation of the Palestinian territory, particularly the closure of the Gaza Strip, affects the social determinants of Palestinian health, as the OPt bears one of the highest burdens of mental disorders in the eastern Mediterranean region [3]. This is supported by the WHO report which described the chronic mental health situation in the Opt, as a result of Israeli occupation and violence. According to the WHO, mental illness is 'one of the most important public health challenges' in the OPt. In Gaza Strip in particular, more than half of children affected by the 
conflict may be affected by post-traumatic stress disorder', while 'an estimated 210,000 people or more than one in 10 people suffer from severe or moderate mental health disorders in the Gaza Strip [34].This was actually seen from the experience of the second author of the article who is working as a head nurse of adult oncology and hematology ward, most of the cancer patients came from the Gaza strip referred to An- Najah National University Hospital-Nablus in West Bank, complain of many obstacles started from the beginning of their journey to access health care services which are not present in the Gaza strip. The difficulties include delay, the waiting at Erez and Qalandia barriers ,beside transportation costs and Israeli investigations before crossing the barriers. Patients arrived tired, frustrated, and anxious, stressed and in some cases reported depressed emotions and fear from reexperiencing difficulties that increase the psychological burden and affect their mental health. This is supported by a descriptiveanalytical study done in 2017 for cancer patients from the Gaza Strip, which indicated that they are suffering from anxiety and depression due to the siege which affects their medical condition negatively and their immune system. [35] From the experience of the second author as mental health consultant; some of the patients were reported they were being asked to work with Israeli intelligence services (spy) to get access to the health care services.

For patients from the West Bank referred to East Jerusalem, they must also cross barriers. Palestinians who live in East Jerusalem have differential access to health services compared to Palestinians from the West Bank. Palestinians in East Jerusalem can apply to Israeli authorities for a 'residency' status that entitles them to Israeli health services, on the condition that they continue to live or work in East Jerusalem or Israel [10]. That shows, there is inequality in accessing health care services for Palestinians, according to living regions, fragmented by Separation Wall. Most suffering is shown in the Gaza Strip followed by West Bank and East Jerusalem due to military Israeli occupation, which lowers the quality of life and leads to mental health problems. On the other hand, the Palestinian refugee's dignity and mental health were affected due to inequality to access health care services [8] .Difficulties in access to health care needs, affect the quality of life as supported by Ibraham Maslow's theory of the Hierarchy of Needs which where safety comes first.[36]

Patients who need to be accompanied by a companion, risk being delayed in obtaining their medical care, if Israeli authorities refuse or delay approving their permits until they change their companions. Companions can be arbitrarily denied permits and reasons are not given. Children should not be denied accompaniment by their parents, and should not be delayed medical care due to a request to change companions. Therefore, they become worried and increases their stress levels, anxiety and depression. Traveling outside of Gaza for medical treatment for a serious medical condition can be stressful for any patient and physically difficult to negotiate, and all patients need family or social support in the hospital for their psychological well-being [8]. Which affects negatively the patient's emotional state, because the companion takes a supportive role for the patient in the hospital, especially for Gazan children deprived of their parents to stay with them,[37]. Even with a good prognosis, separation during such a critical time is painful for children: babies must be weaned suddenly to travel with another relative, and older children interact with anxiety, refuse to eat, talk or cure completely. Children who have a parent, on the contrary, have stronger vital signs and a much better chance of recovery. "Settling for less when it comes to parental accompaniment compromises the child's recovery prospects and violates their right to health," Majadli says from Augusta Victoria Hospital. [38]

Israeli responses to requests from parents of children in need of specialized medical treatment in outpatient hospitals are unpredictable. Parents are at high risk of arbitrary denial of permits. The health and well-being of children depend on sourcing them with their parents in the hospital. The government's decision to re-establish a new government in 2008 was a very important one. Patients are left in uncertainty by not receiving timely responses to permit applications until the date of their appointment to the hospital has passed. The length of time it takes to process Israeli permits unnecessarily delays their medical treatment. Treatment should give priority to patients and ensure that responses are given before the appointment date at the hospital. [8] that is an increased risk for psychological burden, stress and develop the mental disorder if no adaptation as mentioned in the literature[3][15] [16][22], but oppositely seen in Western countries as high accessibility, continuity, and coordination of care just [39].And Patients in the U.S. have quick access to specialized healthcare services. In other countries, such as Canada, patients bear little or no financial burden, but they face waiting times for such specialized services. The Netherlands, the UK, and Germany provide comprehensive coverage at low pocket costs while maintaining quick access to specialized services[39]. but in Arab countries that politically unstable as Iraq has difficulties in access health care otherwise the transportation issues may delay access to health care services in Arab countries. [40] 
When the patients can't access free health care services and faced them in an unreceptive manner while crossing the Israeli barriers the patient's dignity affected, and the patient's psychological status is affected too as of being the pediatric patient without parents. [8][7]

The delay and denial in a permit application process increase the patient's concern about the appointment that leads to anxiety and access to health is not fully respected to the extent required for population health and well-being and the functioning of the Palestinian health system.

In a clinical experience and research in human environments from a child's perspective in 2005 , that explores the issues facing child and family mental health after traumatized events of conflict zones. The study concluded that children's mental health needs to be varied in terms of crisis, complexity and intimate attachment to their needs for security, food, shelter, education , and family communication, reflecting the difficulty of accessing health-care services that lead to lower quality of life [19]. So the priority needs of Palestinian civilians are to gain their freedom, such as expression, travel, and protection. The unstable environment is constantly causing new mental health problems for civilians. The priority is to establish an effective and supportive mental health system and to stop the occupation as primary prevention.[41]

\section{Conclusion}

Palestinian patients faced many difficulties geographically and psychologically mainly as a result of barriers to the Israeli occupation. Patients from West Bank need permission to access health care services in East Jerusalem or Gaza patients need a permit to access health care services either in East Jerusalem and West Bank need to cross barriers through Separation Wall checkpoint too. More than ten studies and reports supported that there are negative mental health consequences of difficulties in accessing health care services as a result of the Separation Wall, barriers and closures by the Israeli Authority[6][8][9][13][15][19][23] [30][34] These difficulties are represented in the psychological burden, psychological distress, and abuse, emotional stress, negatively affect the dignity and quality of palliative care specifically for cancer patients, and patients feel inequality, insecurity and their quality of life is affected [2][6][8][19][28][32][35] more seen in Gazan patients. On the other hand, there is a negative impact on the work of health-care providers, who need access to health-care places through barriers or road closures represented in psychological and moral suffering[2][9][34]. Frustration and dissatisfaction were reported in women needed to access health care of childbirth [21][22][26][27] and psychological effects among children [6][19][20]. With all the obstacles to access health care services, the Palestinians try to cope with their situation and improve the quality of life and mental health depending on the resilience culture [29] and 'Sumud' [45] which is a Palestinian idea intertwined with ideas of personal and collective resilience [19] [30] [42] Reliance on religious support. [14]

\section{Recommendations}

- We recommend the need for more studies and policies to address inequalities in access to health care within these areas. And further study about mental health consequences concerning limitations among Palestinian patients crossing barriers. We also recommend ending up the Israeli occupation which is the main cause of prohibiting Palestinians from free access to health care services.

\section{Limitations}

Palestine is an occupied country that is seeking independence with a scarcity of resources. Palestine has been described as "uncharted territories" due to a lack of data, resources and records. As a result, there is insufficient data regarding access limitation to health services in Palestine.

\section{Abbreviations}

WHO

world health organization

oPt

Occupied Palestinian territory 


\section{Declarations}

\section{Acknowledgements}

Special thanks to Faculty of Post graduate college-Community Mental Health Nursing Program at AN-Najah National University for their support and offering facilities. In addition to all authors in the field of mental health in Palestine who equipped us with the relevant information for this literature. We would like to thank Miss Hannan Kalbuneh (An-Najah National University Hospital) for proofreading and Zareefa Shaabnah for her review.

\section{Authors' contributions}

MM conceived the idea for the study from which this article is drawn. MB collected the data, analyzed and interpreted the findings and drafted this manuscript. MM supervised the study analysis, interpretation of findings, and made substantive intellectual contributions to the manuscript. All authors read and approved the final manuscript.

\section{Funding}

There is no source of funding for this research.

\section{Availability of data and materials}

This is an evidence synthesis study, all data is available from the primary research studies, or can be circulated from the corresponding author.

\section{Ethics approval and consent to participate}

Not applicable in this study.

\section{Consent for publication}

Not applicable in this study.

\section{Competing interests}

The authors declare that they have no competing interests in this section.

\section{References}

1. Palestine | History, People, \& Religion [Internet]. Encyclopedia Britannica. [cited 2020 Mar 9]. Available from: https://www.britannica.com/place/Palestine

2. Sousa C, Hagopian A. Conflict, health care, and professional perseverance: A qualitative study in the West Bank. Global Public Health. 2011 Jul;6(5):520-33.

3. Charara R, Forouzanfar M, Naghavi M, Moradi-Lakeh M, Afshin A, Vos T, et al. The Burden of Mental Disorders in the Eastern Mediterranean Region, 1990-2013. Maulik PK, editor. PLoS ONE. 2017 Jan 17;12(1):e0169575.

4. Over 700 road obstacles control Palestinian movement within the West Bank. United Nations Office for the Coordination of Humanitarian Affairs - occupied Palestinian territory. [cited 2020 Apr 13]. Available from: https://www.ochaopt.org/content/over-700-road-obstacles-control-palestinian-movement-within-west-bank

5. Sousa C, Hagopian A. Conflict, health care, and professional perseverance: A qualitative study in the West Bank. Global Public Health. 2011 Jul;6(5):520-33.

6. Waterston T, Nasser D. Access to healthcare for children in Palestine. bmjpo. 2017 Nov;1(1):e000115.

7. Kitamura A, Jimba M, McCahey J, Paolucci G, Shah S, Hababeh M, et al. Health and dignity of Palestine refugees at stake: a need for international response to sustain crucial life services at UNRWA. The Lancet. 2018 Dec;392(10165):2736-44.

8. Manenti A. Report of a field assessment of health conditions in the occupied Palestinian territory. 2017:29. 
9. Ranaweera S, World Health Organization, editors. Current information on use and harm from alcohol in the WHO South-East Asia region. New Delhi: World Health Organization, Regional Office for South-East Asia; 2007. 111 p. (Alcohol control series).

10. Zheng Z, Gu S, Lei Y, Lu S, Wang W, Li Y, et al. Safety Needs Mediate Stressful Events Induced Mental Disorders. Neural Plasticity 2016; 2016:1-6. DOI:10.1155/2016/8058093.

11. ESCR General Comment No. 12 (1999) on the Right to Adequate Food (Article 11 of the Covenant). Economic, Social, and Cultural Rights. DOI:10.9783/9780812205381.336.

12. Report of the Special Rapporteur on the Situation of Human Rights in the Palestinian Territories Occupied since 1967, Richard Falk (Sep. 16, 2013). The Palestine Yearbook of International Law Online 2014;17:374-402. DOI:10.1163/2211614101701025.

13. Manenti A. Report of a field assessment of health conditions in the oPt. 2015:29.

14. Sousa CA. Political violence, health, and coping among Palestinian women in the West Bank. American Journal of Orthopsychiatry. 2013 Oct;83(4):505-19.

15. Vitullo A, Soboh A, Oskarsson J, Atatrah T, Lafi M, Laurance T. Barriers to the access to health services in the oPt: a cohort study. The Lancet. 2012 Oct;380:S18-9.

16. Mataria A, Giacaman R, Stefanini A, Naidoo N, Kowal P, Chatterji S. The quality of life of Palestinians living in chronic conflict: assessment and determinants. The European Journal of Health Economics 2008;10:93-101. DOI:10.1007/s10198-008-01065.https://pubmed.ncbi.nlm.nih.gov/18437435-the-quality-of-life-of-palestinians-living-in-chronic-conflict-assessment-anddeterminants/

17. Funding shortages undermine continuity of mobile health clinics in vulnerable West Bank communities [Internet]. United Nations Office for the Coordination of Humanitarian Affairs - occupied Palestinian territory. 2018 [cited 2020 Apr 11]. Available from: https://www.ochaopt.org/content/funding-shortages-undermine-continuity-mobile-health-clinics-vulnerable-west-bank

18. Wick L. Building the Infrastructure, Modeling the Nation: The Case of Birth in Palestine. Cult Med Psychiatry. 2008 Sep;32(3):328-57.

19. Jones, Lynne. "Responding to the Needs of Children in Crisis." International Review of Psychiatry, vol. 20, no. 3, 2008, pp. 291303., DOI:10.1080/09540260801996081.

20. Mataria A, Giacaman R, Stefanini A, Naidoo N, Kowal P, Chatterji S. The quality of life of Palestinians living in chronic conflict: assessment and determinants. The European Journal of Health Economics 2008;10:93-101. DOI:10.1007/s10198-008-0106-5.

21. Giacaman R, Abu-Rmeileh NME, Wick L. The limitations on choice: Palestinian women's childbirth location, dissatisfaction with the place of birth and determinants. The European Journal of Public Health. 2007 Feb 1;17(1):86-91. https://academic.oup.com/eurpub/article/17/1/86/466322

22. Leone T, Alburez-Gutierrez D, Ghandour R, Coast E, Giacaman R. Maternal and child access to care and intensity of conflict in the oPt: a pseudo-longitudinal analysis (2000-2014). Confl Health. 2019 Dec;13(1):36.

23. Murphy MC. Israeli barriers kill women in childbirth, says new study. The Electronic Intifada. 2011 [cited 2020 Mar 21]. Available from: https://electronicintifada.net/content/israeli-barriers -kill-women-childbirth-says-new-study/10145

24. Palestinian pregnant women giving birth at Israeli checkpoints - HRC seventh session - UNHCHR report. Question of Palestine. [cited 2020 Apr 13]. Available from: https://www.un.org/unispal/document/auto-insert-186867/

25. Year-in-review: Worst abuses against Palestinian children in 2017. Defense for Children Palestine. [cited 2020 Apr 13]. Available from: https://www.dci-palestine.org/year_in_review_worst_abuses_against_palestinian_children_in_2017

26. Bailony MR, Hararah MK, Salhab AR, Ghannam I, Abdeen Z, Ghannam J. Cancer registration and healthcare access in West Bank, Palestine: A GIS analysis of childhood cancer, 1998-2007. Int J Cancer. 2011 Sep 1;129(5):1180-9.

27. WHO situation reports (2015), http://www.emro.who.int/pse/palestine-infocus/situation-reports.html

28. Bailony MR, Hararah MK, Salhab AR, Ghannam I, Abdeen Z, Ghannam J. Cancer registration and healthcare access in West Bank, Palestine: A GIS analysis of childhood cancer, 1998-2007. Int J Cancer. 2011 Sep 1;129(5):1180-9.

29. Marie M, Hannigan B, Jones A. Mental health needs and services in the West Bank, Palestine. Int J Ment Health Syst. 2016 Dec;10(1):23. 
30. Marie M, Hannigan B, Jones A. Challenges for nurses who work in community mental health centres in the West Bank, Palestine. Int J Ment Health Syst. 2017 Jan 3;11:3-3.

31. Failing Gaza healthcare system after 10-year blockade barely handling 2,000+ live fire injuries [Internet]. B'Tselem. [cited 2020 Mar 21]. Available from: https://www.btselem.org/gaza_strip/20180510_failing_healthcare_system_barely_handling_injuries

32. WHO EMRO | Gaza patients' painful journey to cancer treatment | Palestine-news | Palestine. [cited 2020 Mar 23]. Available from: http://www.emro.who.int/pse/palestine-news/gaza-patients-painful-journey-to-cancer-treatment.html

33. Referral of patients from the Gaza Strip - WHO monthly report (December 2013) (30 January 2014) [Internet]. [cited 2020 Apr 13]. Available from:

https://unispal.un.org/DPA/DPR/unispal.nsf/eed216406b50bf6485256ce10072f637/c0bdfdc0b702094785257c760070becc? OpenDocument

34. WHO details mental health impact for Palestinians under Israeli occupation. Middle East Monitor. 2019 [cited 2020 Mar 13 ]. Available from: https://www.middleeastmonitor.com/20190523-who-details-mental-health-impact-for-palestinians-under-israeloccupation/

35. Bseiso RA, Thabet AM. The Relationship between Siege Stressors, Anxiety, and Depression among Patients with Cancer in Gaza Strip. Health Science Journal [Internet]. 2017 May 4 [cited 2020 May 14];11(2). Available from: https://www.hsj.gr/abstract/the-relationship-between-siege-stressors-anxiety-and-depression-among-patients-with-cancer-ingaza-strip-19052.html

36. Zheng Z, Gu S, Lei Y, Lu S, Wang W, Li Y, et al. Safety Needs Mediate Stressful Events Induced Mental Disorders. Neural Plasticity 2016; 2016:1-6. DOI:10.1155/2016/8058093.

37. Segev Z, Arif AA, Rohrer JE. Activity Limitations and Healthcare Access as Correlates of Frequent Mental Distress in Adults 65 Years and Older: A Behavioral Risk Factor Surveillance Study-2008. J Prim Care Community Health. 2012 Jan;3(1):17-22.

38. JERUSALEM PG| 27/2/2020. LWF and partners advocate for Palestinian children's access to health care. The Lutheran World Federation. 2020 [cited 2020 Apr 13]. Available from: https://www.lutheranworld.org/news/lwf-and-partners-advocatepalestinian-childrens-access-health-care

39. How the U.S. Health Care System Compares Internationally. [cited 2020 Apr 13]. Available from: https://www.commonwealthfund.org/publications/fund-reports/2014/jun/mirror-mirror-wall-2014-update-how-us-health-caresystem

40. Batniji R, Khatib L, Cammett M, Sweet J, Basu S, Jamal A, et al. Governance and health in the Arab world. Lancet. 2014/01/20. 2014 Jan 25;383(9914):343-55.

41. Giacaman R, Neil A, Summerfield D. Establishing a mental health system in the occupied Palestinian territories. Int Psychiatry. 2005;9:16-8.

42. Marie $M$, Hannigan B, Jones A. Resilience of nurses who work in community mental health workplaces in Palestine. Int $J$ Ment Health Nurs. 2017 Aug;26(4):344-354. doi: 10.1111/inm.12229. Epub 2016 Jun 13. PMID: 27293015.

43. Marie, M., Shaabna, Z., \& Saleh, M. (2020). Schizophrenia in the context of mental health services in Palestine: a literature review. International journal of mental health systems, 14, 44. https://doi.org/10.1186/s13033-020-00375-6

44. Marie M, SaadAdeen S, Battat M. Anxiety disorders and PTSD in Palestine: a literature review. BMC Psychiatry. 2020 Oct 16;20(1):509. doi: 10.1186/s12888-020-02911-7. PMID: 33066736; PMCID: PMC7566157.

45. Marie M, Hannigan B, Jones A. Social ecology of resilience and Sumud of Palestinians. Health (London, England: 1997) .2018 Jan 1;22(1):20-35. Available from: https://www.ncbi.nlm.nih.gov/pubmed/28177266

46. Marie M, SaadAdeen S, Mental Health Consequences of Home Demolition Policy towered Palestinians: Literature review. Publication in progress

\section{Supplementary Files}

This is a list of supplementary files associated with this preprint. Click to download. 
- AppendixesA.docx

- tablemattrixMM.docx

- PRISMAMM.docx 